\title{
DESEMPENHO PRODUTIVO DE FRANGOS DE CORTE EM DIFERENTES SISTEMAS DE INSTALAÇÕES SEMICLIMATIZADAS NO SUL DO BRASIL
}

Irene Menegali ${ }^{1}$, Fernando da Costa Baêta $^{2}$, Ilda de Fátima Ferreira Tinôco ${ }^{3}$, Marcelo Bastos Cordeiro ${ }^{4}$, Maria Clara de Carvalho Guimarães ${ }^{5}$

\section{RESUMO}

O manejo do ambiente térmico na fase inicial da produção de frangos de corte é fundamental para o desempenho zootécnico das aves. Neste trabalho, objetivou-se avaliar o conforto térmico do ambiente e o desempenho zootécnico de frangos de corte, criados em dois diferentes sistemas de ventilação: com pressão negativa e com pressão positiva, durante dois ciclos completos de produção, em condições de inverno, na região sul do Brasil. Com base nos resultados das variáveis ambientais, observou-se que, na primeira semana de vida, as médias de temperaturas estiveram abaixo da faixa correspondente ao conforto térmico por animal, e, para a umidade relativa do ar entre 65 e $70 \%$ para ambos os tratamentos. Foram observados níveis ideais para o conforto das aves. Em relação aos índices de desempenho produtivo, verificou-se que todos, em ambos os sistemas de acondicionamento do ambiente, na fase inicial e final, não apresentaram diferença entre si, posicionando-se dentro da faixa considerada compatível com os valores médios obtidos pela avicultura de corte do Brasil.

Palavras-chave: sistemas de ventilação, ambiente térmico, avicultura de corte, desempenho animal

\section{POULTRY PERFORMANCE IN DIFFERENT HALF-ACCLIMATIZED FACILITY SYSTEMS IN THE SOUTH OF BRAZIL}

\begin{abstract}
The handling of the thermal environment in the initial phase of commercial broiler chicken production is fundamental for the zootechnic performance of fowls. This study was done to analyze the thermal environmental comfort and the zootechnic performance of broiler chickens grown in two different half-acclimatized ventilation systems: one with negative pressure and the other with positive pressure, during two complete cycles under winter conditions on southern Brazil. Based on the results of the environmental variables, it could be noticed that, on the first week of life, the temperature averages were below the zone which corresponds to the animal thermal comfort zone, and, the air humidity measurements between 65 and $70 \%$ for both treatments, required levels for the poultry comfort. In relation to the poultry productive performance indexes, it was found that all were within the range considered as desirable, relative to the average values obtained by the Brazilian broiler chicken production.
\end{abstract}

Keywords: ventilation system, thermal environment, broiler chicken production, animal performance

Recebido para publicação em 24/02/2010. Aprovado em 12/04/2010

1- Prof ${ }^{a}$. Adjunta I, D.S., Instituto de Ciências Agrárias - UFMG, imenegali@ufmg.br

2- Prof. Titular, Ph.D., Departamento de Engenharia Agrícola - UFV,baeta@ufv.br

3- Profa . Associada, D.S., Departamento de Engenharia Agrícola - UFV, iftinoco@ufv.br

4- Doutor em Engenharia Agrícola, mb cordeiro@yahoo.com.br

5- Prof ${ }^{a}$. Adjunta I, D.S., Faculdade de Ciências Agrárias - UFVJM,, mclaracg@yahoo.com.br 
INTRODUÇÃO

O agronegócio é um dos setores da economia mundial em que o Brasil é realmente competitivo. Fatores como clima favorável, disponibilidade de terras agricultáveis, autossuficiência em grãos, dentre outros, fizeram com que o país atingisse o posto de maior fornecedor mundial de vários produtos e o maior exportador de carne bovina e carne de frango (UBA, 2006).

O frango de corte comercial é um dos animais com maior rapidez de desenvolvimento e eficiência nutricional. Em vista disso, a avicultura industrial alcançou notável potencial para prover aos consumidores uma fonte proteica de baixo custo.

A maioria dos sistemas de produção animal utiliza instalações que têm, como principais características, o confinamento de número elevado de indivíduos por área e a consequente restrição do espaço de locomoção. Estas características demandam que as instalações atendam, entre outras necessidades, às exigências de conforto térmico dos animais (JENTZSCH, 2002).

Assim, dentre os fatores do ambiente, os térmicos são aqueles que afetam mais diretamente a ave, pois comprometem sua função vital mais importante, que é a manutenção de sua homeotermia (BAÊTA \& SOUZA, 1997). Verifica-se, por isso, que as novas exigências do mercado quanto à questão ambiental, à segurança alimentar e ao bem- estar animal passam invariavelmente pelo ambiente térmico, conforme observado por Tinôco (1988).

Para as condições de instalações avícolas brasileiras, predominantemente abertas, utilizam-se dois tipos de ventilação: por pressão negativa e por pressão positiva, de acordo com a posição em que são colocados os equipamentos de ventilação. No sistema de pressão negativa, os exaustores succionam o ar do interior para fora das instalações, sendo necessária uma vedação perfeita das coberturas e laterais (TINÔCO \& RESENDE, 1997). No sistema de ventilação positiva, os ventiladores empurram o ar para dentro do galpão (MORAES, 2002). Sendo assim, para cada um dos diferentes tipos de ventilação ocorrem zonas de pressão diferenciadas no interior do alojamento, o que pode comprometer o resultado do ambiente térmico final e, consequentemente, o desempenho animal.

$\mathrm{Na}$ fase inicial da vida da ave, a ventilação só tem como finalidade a renovação higiênica do ar. No sistema de ventilação negativa, a fase de ventilação mínima e higiênica é garantida com o uso de um a dois exaustores, com funcionamento acionado por temporizadores que garantam, no máximo, de uma a seis renovações de ar por hora (CURTIS, 1983), de maneira a garantir a qualidade do ar sem comprometer negativamente a temperatura do ambiente. No sistema de ventilação positiva convencional, não há critérios quanto à ventilação higiênica ou mínima e a renovação se dá, ao acaso, pela abertura das cortinas nos períodos de visitas dos tratadores.

Erros na fase inicial podem gerar problemas graves no desempenho avícola, sendo que muito pouco se conhece sobre esses efeitos para as condições dos galpões abertos no Brasil.

Em função do exposto, objetivou-se com este trabalho analisar o conforto térmico ambiente e o desempenho produtivo de frangos de corte (fêmeas leves), criados em aviários semiclimatizados com dois diferentes sistemas de ventilação: com pressão negativa (SVN) e com pressão positiva (SVP), durante o período de aquecimento (fase inicial da vida da ave) e no período pós-aquecimento, em condições de inverno, na região sul do Brasil, Estado de Santa Catarina, durante dois ciclos completos de criação. Os efeitos dos dois sistemas de acondicionamento serão confrontados com os valores de desempenho animal.

\section{MATERIAL E MÉTODOS}

Este experimento foi desenvolvido em instalações avícolas comerciais, integradas à empresa Perdigão Agroindustrial S.A., situada no município de Videira, região oeste do Estado de Santa Catarina, cujas coordenadas geográficas são: latitude $27^{\circ} 00^{\prime}$ $30^{\prime \prime}$ Sul e longitude $51^{\circ} 09^{\prime} 06^{\prime \prime}$ Oeste; altitude de $750 \mathrm{~m}$.

A região apresenta clima do tipo temperado úmido; estações bem definidas, com temperatura média anual de $17,1^{\circ} \mathrm{C}$ e variação média de $20^{\circ} \mathrm{C}$ no verão e $11^{\circ} \mathrm{C}$ no inverno (EPAGRI, 2005).

A pesquisa foi conduzida durante o período de julho a setembro de 2004 (estação de inverno), sendo que as práticas de manejo das aves seguiram as orientações técnicas habitualmente utilizadas pela empresa. A coleta de dados experimentais compreendeu o ciclo completo de dois lotes de criação sucessivos, com duração aproximada de 33 dias para cada lote. As aves disponibilizadas para este experimento eram da linhagem COBB (fêmeas leves para exportação). 
O experimento foi conduzido em duas instalações de um mesmo setor de produção, posicionados lado a lado, com orientação de seus eixos longitudinais no sentido Leste-Oeste, dimensões de 100 x $12 \mathrm{~m}$ e pé-direito de $2,80 \mathrm{~m}$.

As instalações experimentais foram compostas de diferentes sistemas de acondicionamento ambiente, constituindo dois tratamentos: a) sistema de ventilação por pressão negativa (SVN), e b) sistema de ventilação por pressão positiva (SVP).

A instalação semiclimatizada com ventilação por pressão negativa, utilizada no experimento, possuía cortinas laterais externas, estrutura de cobertura metálica com telhas de zinco, sem forração. O sistema de ventilação era constituído de sete exaustores, com vazão de $560 \mathrm{~m}^{3} / \mathrm{min}$ cada, posicionados em uma das extremidades do galpão. A entrada de ar (aberturas) localizava-se na extremidade oposta. O sistema de nebulização interna era composto de linhas de nebulização espaçadas a cada $3 \mathrm{~m}$, posicionadas perpendicularmente ao comprimento do galpão, com bicos nebulizadores de média pressão a cada 2,0 m. O funcionamento do sistema era controlado automaticamente com umidostato e termostato.

A instalação com ventilação por pressão positiva era equipada com cortinas laterais externas e sobrecortina, fixadas na parte interna do aviário. Possuía, ainda, cobertura com telhas de barro e forro de lona plástica. Os comedouros eram automatizados e o manejo de cortinas manual. Os ventiladores axiais, com vazão de $300 \mathrm{~m}^{3} / \mathrm{min}$ cada, foram dispostos alternadamente, e aos pares, a cada $9 \mathrm{~m}$ de distância entre pares. Esse sistema só entrou em funcionamento após a fase de aquecimento, sendo que a ventilação mínima era mantida apenas pela aberturas das cortinas, nos momentos de vistoria do aviário pelo tratador.

O sistema de aquecimento a gás foi similar para ambos os aviários e obteve distribuição idêntica em ambas as instalações, utilizando-se uma campânula infravermelha para cada 1200 pintinhos, posicionadas a 1,10 $\mathrm{m}$ da cama, fazendo um ângulo de $45^{\circ}$ com o plano horizontal, distribuídas de maneira alternada, visando à uniformidade no aquecimento do pinteiro.

Foram realizadas continuamente medições diárias das variáveis ambientais: temperatura de bulbo seco, umidade relativa e temperatura de globo negro. Os instrumentos específicos para leitura das variáveis do ambiente foram instalados em três pontos, equidistantes, ao longo do comprimento de cada instalação, posicionados a uma altura de $0,30 \mathrm{~m}$ do piso. A partir desses dados foram também calculados os índices de temperatura de Globo Negro e Umidade.

As medições foram realizadas com o uso de dataloggers de leitura contínua, em intervalos de 15 minutos, durante todo o período experimental, totalizando 96 horários de coleta por dia. Os sensores acoplados a dataloggers da marca Testo, modelo $\mathrm{H} 1$, possuíam resolução de $0,1{ }^{\circ} \mathrm{C}$ e $1 \%$ e acurácia de $\pm 0,5{ }^{\circ} \mathrm{C}$ e $\pm 1 \%$ para medição de temperatura e umidade relativa, respectivamente.

Para avaliar o desempenho produtivo dos animais, foram utilizados os índices zootécnicos mais comuns, ou seja, peso vivo (PV), consumo de ração (CR), ganho de peso (GP), conversão alimentar (CA) e taxa de mortalidade (TM).

Para obtenção do peso vivo das aves, os animais foram pesados, semanalmente, aos 7, 14, 21 e 28 dias de idade, por meio de amostragem aleatória de 250 aves nos SVN e SVP. O ganho de peso médio semanal foi obtido pela diferença entre o peso vivo médio final e inicial de cada semana. A ração consumida, semanalmente, aos 7, 14, 21 e 28 dias, foi determinada com base no fornecimento das rações de acordo com as exigências da linhagem, as necessidades nutritivas e de arraçoamento dos animais. Os cálculos de conversão alimentar foram realizados por meio da relação entre os valores de consumo de ração e de peso vivo das aves, analisados nas quatro semanas de observações. A taxa de mortalidade, em percentagem, foi obtida por meio da relação entre o número de aves mortas pelo número total de aves alojadas, avaliado semanalmente em cada instalação, em todo o período experimental.

Para a avaliação estatística, o período experimental foi divido em quatro fases, correspondentes às semanas de observação. Considerou-se, para primeira semana, de 1 a 7 , para a segunda, de 8 a 14, para a terceira, de 15 a 21 e para a quarta, de 22 a 28 dias.

Para o estudo das variáveis ambientais, o experimento foi disposto segundo um esquema de parcelas subdivididas, contendo, nas parcelas, os tratamentos e, nas subparcelas, os horários (96 horários), no delineamento em blocos casualizados (D.B.C), com duas repetições (correspondentes aos ciclos de produção).

Os dados foram submetidos à análise de variância. Para o fator qualitativo (tratamentos), as médias foram comparadas utilizando-se o teste $\mathrm{F}$ a $5 \%$ de probabilidade.

Para o estudo do desempenho produtivo, PV, CA, 
TM, os tratamentos foram dispostos num esquema de parcelas subdivididas, contendo, nas parcelas, os tratamentos SVN e SVP e, nas subparcelas, as semanas de observação, no delineamento em blocos casualizados com duas repetições.

\section{RESULTADOS E DISCUSSÃO}

\section{Ambiente Térmico}

No Quadro 1, apresenta-se o resultado das análises de variâncias referentes aos efeitos dos tratamentos e das horas $(\mathrm{H})$, com relação à média horária no interior das instalações, para a variável ambiental temperatura do ar (T). Neste trabalho, optou-se pelo desdobramento das interações (Tratamento x H), independentemente de elas serem ou não significativas, uma vez que $o$ objetivo principal foi diagnosticar os dados térmicos em ambos os sistemas de ventilação, tendo como base o manejo padrão da maioria das Indústrias Avícolas no sul do país.

Na Figura 1, estão representados os resultados dos valores médios de temperatura do ar, observados nos ambientes interno e externo, referentes à primeira e segunda semanas, correspondendo aos tratamentos SVN e SVP.

Verifica-se, de forma geral, que, independentemente do tratamento (SVN e SVP), as médias de temperatura correspondentes à primeira semana de vida das aves estiveram sempre abaixo da faixa ideal da zona de conforto térmico, ou seja, apresentaram-se entre 26,57 e $30,91{ }^{\circ} \mathrm{C}$, sendo que a temperatura ideal para o bom desenvolvimento das aves situa-se entre 32 e $34{ }^{\circ} \mathrm{C}$ (MACARI et al., 2002).
Figura 1. Médias de temperatura do ar no ambiente interno e externo, em função dos horários durante a primeira e segunda semana de vida das aves.

Primeira Semana

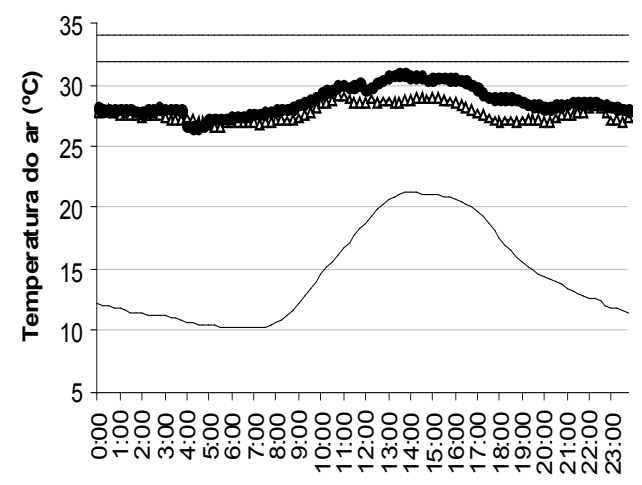

Segunda semana

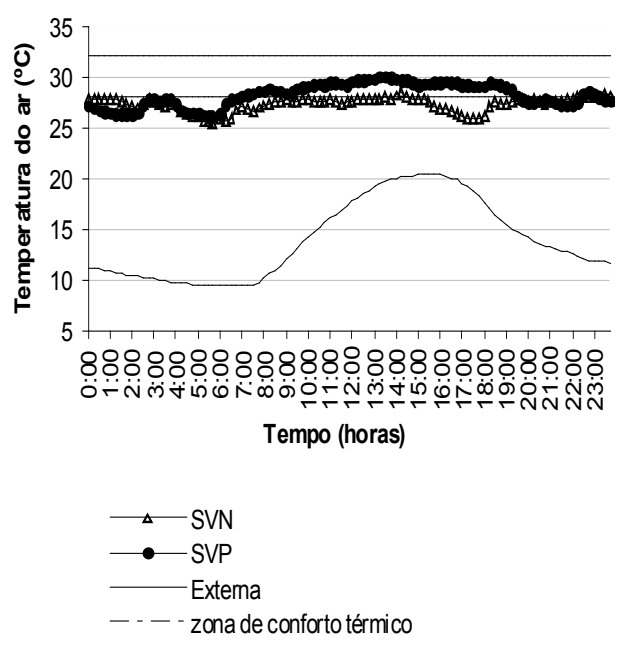

Quadro 1. Resumo das análises de variância referentes aos efeitos dos tratamentos sobre a temperatura do ar (T) no interior das instalações

\begin{tabular}{lccccc}
\hline \multirow{2}{*}{ FONTE DE VARIAÇÃO } & G.L. & \multicolumn{4}{c}{ TEMPERATURA DO AR } \\
\cline { 3 - 6 } & & \multicolumn{4}{c}{ QUADRA DOS MÉDIOS } \\
\cline { 2 - 6 } & 1 & $48,2788 *$ & $229,853 * *$ & $308,032 * *$ & $34,6804 *$ \\
LOTE & 1 & $95,0028 *$ & $84,2864 * *$ & $4,1489 *$ & $54,0547 *$ \\
TRATAMENTO & 1 & 18,1145 & 0,0602 & 1,0887 & 11,3436 \\
RESÍDUO (a) & 95 & $3,2146 * *$ & $2,2793 \mathrm{n} . \mathrm{s}$ & $4,2390 * *$ & $13,2157 * *$ \\
HORA & 95 & $0,4247 \mathrm{n} . \mathrm{s}$ & $1,3949 \mathrm{n} . \mathrm{s}$ & $0,2357 \mathrm{n} . \mathrm{s}$ & $1,1798 * *$ \\
HORA X TRAT. & 190 & 2,0382 & 3,6368 & 1,8742 & 0,6637 \\
RESÍDUO (b) & & 15,08 & 0,88 & 3,91 & 13,34 \\
\hline C.V. (\%) PARCELA & & 5,06 & 6,87 & 5,13 & 3,23 \\
C.V. (\%) SUBPA RCELA & & & & & $2^{\mathrm{a}}$ s semana \\
\hline
\end{tabular}


É importante ressaltar que, na primeira e segunda semana de alojamento (primeiros 14 dias de vida das aves), em que se exigem valores de temperaturas acima de $28^{\circ} \mathrm{C}$ para que os pintinhos se desenvolvam de maneira satisfatória, foram fornecidas fontes suplementares de calor, por meio de campânulas infravermelhas.
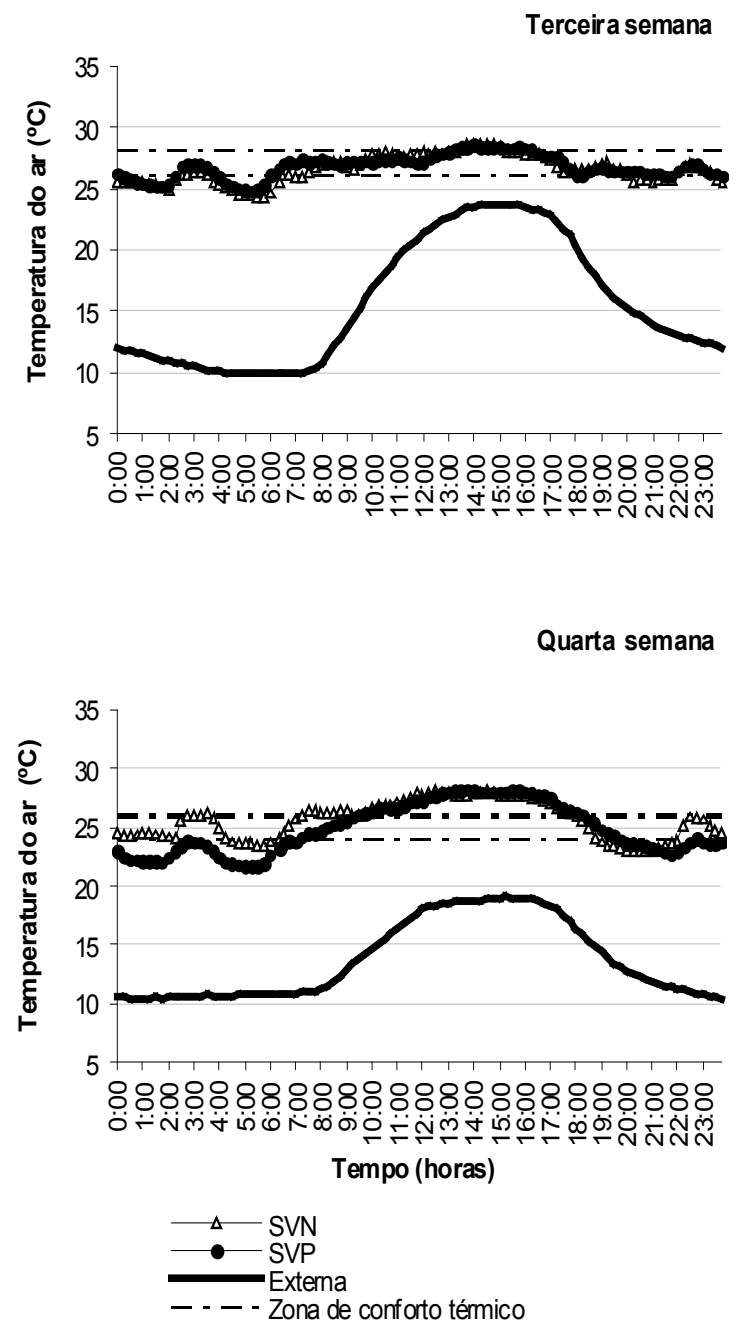

Figura 2. Médias de temperatura do ar no ambiente interno e externo, em função dos horários durante a terceira e quarta semana de vida das aves.
Os valores médios de temperatura observados, referentes aos tratamentos na terceira semana, mostram comportamento semelhante para os dois tratamentos, estando em condições de conforto ou próximo a elas na maioria dos períodos (Figura 2). A faixa de conforto térmico para a terceira semana de vida dos frangos de corte é de 26 a $28^{\circ} \mathrm{C}$.

Pelas Figuras 1 e 2, verificou-se que os valores médios de temperatura do ar ambiente externo, circunvizinho às instalações, foram bem inferiores aos obtidos para ambos os sistemas de acondicionamento de ambientes internos, com os menores valores observados no período compreendido entre 22 e $08 \mathrm{~h}$ da manhã, demonstrando a efetividade do isolamento térmico do aviário no sentido de manutenção da temperatura ambiente.

Mesmo com o aquecimento na primeira semana, não se conseguiu atingir os níveis ótimos de temperatura do ar, fato que se deve ao inverno muito rigoroso, que incide na região sul do Brasil e, ainda, às possíveis falhas de manutenção nos sistemas de aquecimento, fazendo com que não alcançassem a máxima eficiência necessária. Deduz-se, também, a ocorrência de falhas nos fechamentos das instalações, que podem ter apresentado fugas de calor por pontos onde não se conseguiu vedação total, como furos nas lonas de vedação lateral e de forração, dentre outros.

E, ainda, a incidência de inverno rigoroso, com grande amplitude térmica entre o ambiente externo e interno, dificultou a supressão para o aquecimento satisfatório, conforme pode ser observado entre os horários de $00 \mathrm{~h}$ às $07 \mathrm{~h}$.

Os resultados das análises de variância, referentes aos tratamentos com relação à média horária (Horas) da umidade Relativa do ar (UR), tomada internamente nos galpões, estão apresentados no Quadro 2.

Quadro 2. Resumo das análises de variância referentes aos efeitos dos tratamentos sobre a umidade relativa do ar (UR) no interior das instalações

\begin{tabular}{|c|c|c|c|c|c|}
\hline \multirow{3}{*}{ FONTE DE VARIA ÇÃO } & \multirow{3}{*}{ G.L. } & \multicolumn{4}{|c|}{ UMIDADE RELATIVA } \\
\hline & & \multicolumn{4}{|c|}{ QUA DRA DOS MÉDIOS } \\
\hline & & $1^{\mathrm{a}}$ semana & $2^{a}$ semana & $3^{a}$ semana & $4^{a}$ semana \\
\hline LOTE & 1 & $7718,084 *$ & $4926,53 * *$ & $3742,12 *$ & 326,799 n.s \\
\hline TRATAMENTO & 1 & 107,798 n.s & $40,0008 \mathrm{n} . \mathrm{s}$ & 2966 n.s & $4929,3 * *$ \\
\hline RESÍDUO (a) & 1 & 2438,039 & 251,517 & 3298,77 & 527,297 \\
\hline HORA & 95 & $14,54763 * *$ & $24,1275 * *$ & $233,864 * *$ & $410,296 * *$ \\
\hline HORA XTRAT. & 95 & $4,0770 \mathrm{n} . \mathrm{s}$ & $14,3275 \mathrm{n} . \mathrm{s}$ & $5,22298 \mathrm{n} . \mathrm{s}$ & $17,866 * *$ \\
\hline RESÍDUO (b) & 190 & 8,613009 & 14,6301 & 25,9207 & 2,96776 \\
\hline C. V. $(\%)$ PA RCELA & & 15,08 & 21,58 & 78,24 & 32,16 \\
\hline C.V. $(\%)$ SUBPA RCELA & & 5,06 & 5,21 & 6,94 & 2,41 \\
\hline
\end{tabular}


Na Figura 3, estão representados os resultados médios de umidade relativa do ar (UR), observados nos ambientes interno e externo, referentes à primeira semana de vida das aves e correspondentes aos dois tratamentos, SVN e SVP.

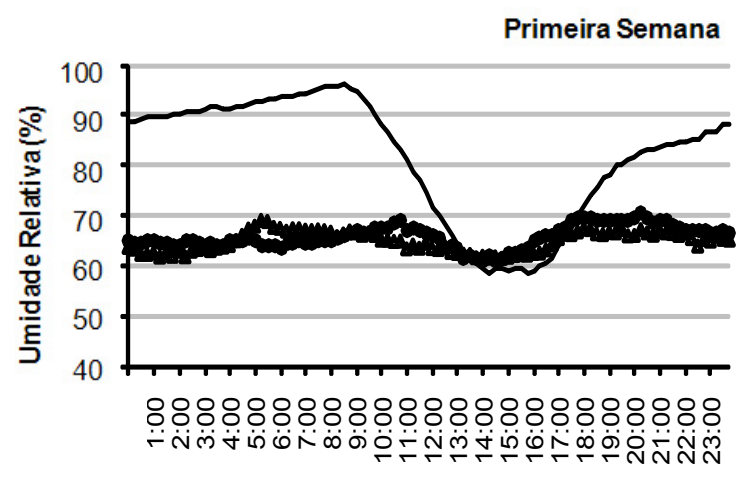

Segunda Semana

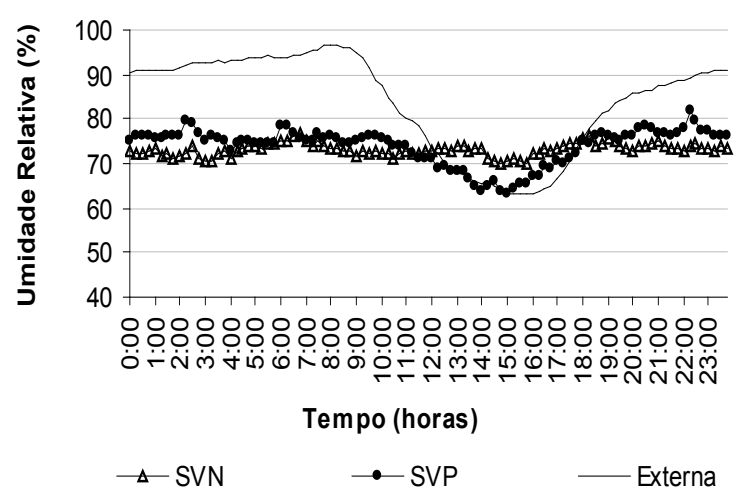

Figura 3. Médias da umidade relativa do ar (UR) no ambiente interno e externo, em função dos horários na primeira e segunda semana de vida das aves.

De forma geral, os valores de UR estiveram entre 60 e $70 \%$ para ambos os tratamentos, o que é desejável, com os menores valores ocorrendo em torno das $14 \mathrm{~h}$.

Baseando-se nas curvas observadas na Figura 3, verificase que os tratamentos SVN e SVP apresentaram os menores valores observados de umidade relativa do ar, às 15 h $45 \min (69,9 \%)$ e 15 h $(63,2 \%)$, respectivamente, indicando condições favoráveis de UR para as aves na segunda semana de vida.

A Figura 4 apresenta as médias de umidade relativa do ar (UR), observadas e estimadas nos ambientes interno e externo, referentes à terceira e quarta semana e correspondendo aos tratamentos SVN e SVP.
Terceira semana
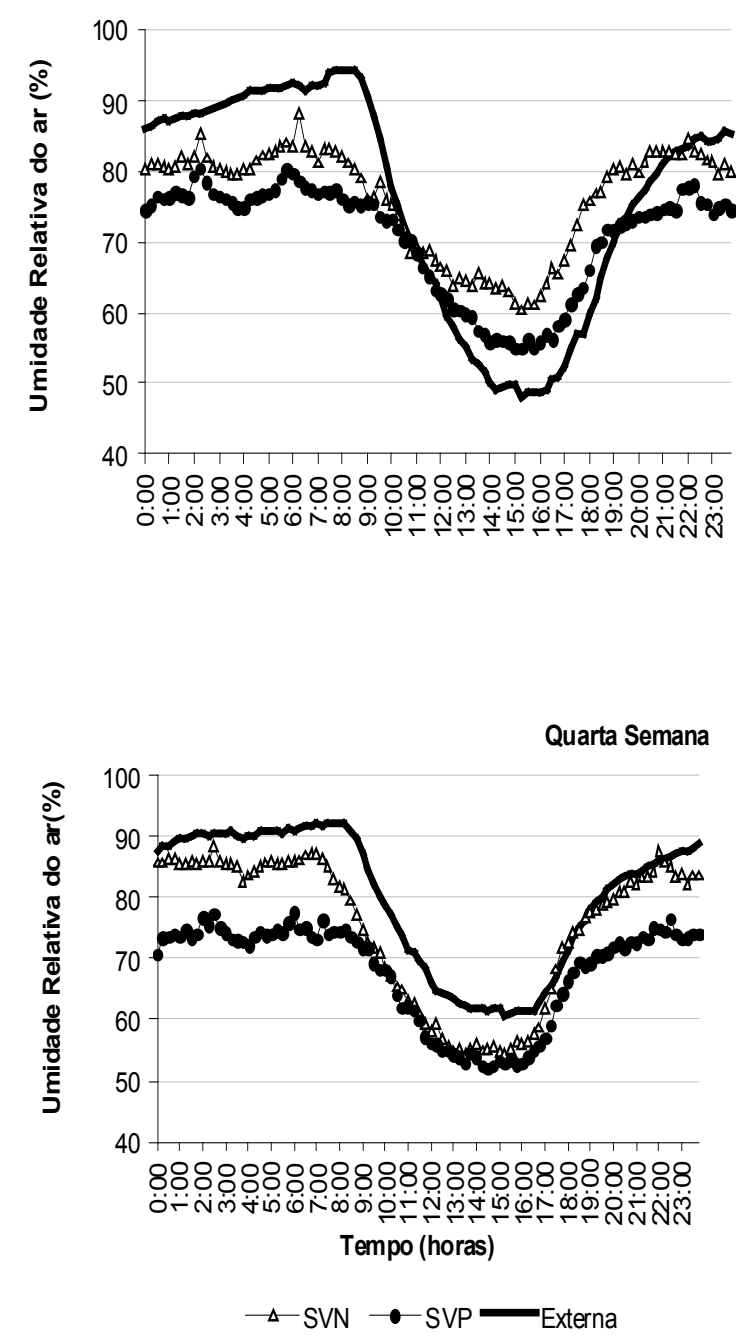

Figura 4. Médias da Umidade relativa do ar (UR) no ambiente interno e externo, em função dos horários na terceira e quarta semana de vida das aves.

Os valores de UR observados no SVN foram, em alguns horários de observação, superiores ao limite recomendado para o conforto das aves, que é de $80 \%$.

Para ambas as instalações observa-se que os valores de UR, na terceira semana de vida das aves, foram decrescentes a partir das $09 \mathrm{~h}$, atingindo valores mínimos de 60,4 e 54,9\% próximo de $15 \mathrm{~h}$ 15 min e $15 \mathrm{~h}$, para os SVN e SVP, respectivamente. É importante ressaltar que nesses dias não houve necessidade do uso de nebulização nem de ventilação, para auxiliar na redução da temperatura do ar, pois, nesta fase de vida das aves a temperatura encontrouse dentro da faixa ideal de conforto.

Pormeio da Figura 4, observa-se que, na quarta semana de vida das aves, os maiores valores médios observados de UR ocorreram no SVN, às 02 h 30 min. Os menores 
valores estimados foram obtidos no tratamento SVP, às 14 h $30 \mathrm{~min}$.

De acordo com Agroceres (1997), a umidade relativa do ar no interior de uma instalação avícola deve permanecer em torno de 50 a $70 \%$, para manter uma boa qualidade de cama, sem que se torne muito seca ou empoeirada. Neste experimento, levando em conta a boa qualidade da cama, os valores médios de UR, observados na primeira semana de vida das aves, atenderam aos índices ideais. Já para o período experimental compreendendo a terceira e quarta semana, na maioria dos horários os valores de UR estiveram acima daqueles recomendados.

Pelas Figuras 3 e 4, observa-se que os valores médios de UR do ar, no ambiente externo circunvizinho às instalações em análise, foram muito superiores aos obtidos para ambos os tratamentos no ambiente interno, com os maiores valores pela manhã, decrescendo até aproximadamente $14 \mathrm{~h}$ e crescendo, novamente, aproximadamente a partir das $17 \mathrm{~h}$.

Os resultados das análises de variância referentes aos tratamentos com relação à média horária (Horas), para o índice de temperatura de globo negro e umidade (ITGU) tomada internamente nos galpões, apresentam-se no Quadro 3.

Na primeira semana de vida das aves, de modo geral não houve diferença para os valores médios de ITGU, entre os tratamentos, em relação aos horários observados, com diferenças significativas apenas entre 06 e 09 h. Observa-se que as médias de ITGU foram maiores no tratamento SVN. Na segunda semana de observação, houve diferença significativa entre os tratamentos em todos os horários observados.

Na Figura 5, estão representados os resultados médios dos valores de ITGU para os tratamentos SVN e SVP, referentes à primeira e segunda semana de vida das aves.

Verifica-se que, em todos os horários da primeira e segunda semana de vida das aves, o ITGU foi maior no tratamento SVN, provavelmente por causa da menor intensidade de ventilação e maior carga térmica advinda da cobertura desta instalação, que é de chapas galvanizadas, o que afeta diretamente a temperatura de globo negro, variável importante deste índice (Figura 5). No SVP, cujo telhado era de telha de barro e possuía forro, esses índices são adequados à produção das aves para a primeira semana de vida dos animais, estando de acordo com os resultados encontrados por Teixeira (1983).
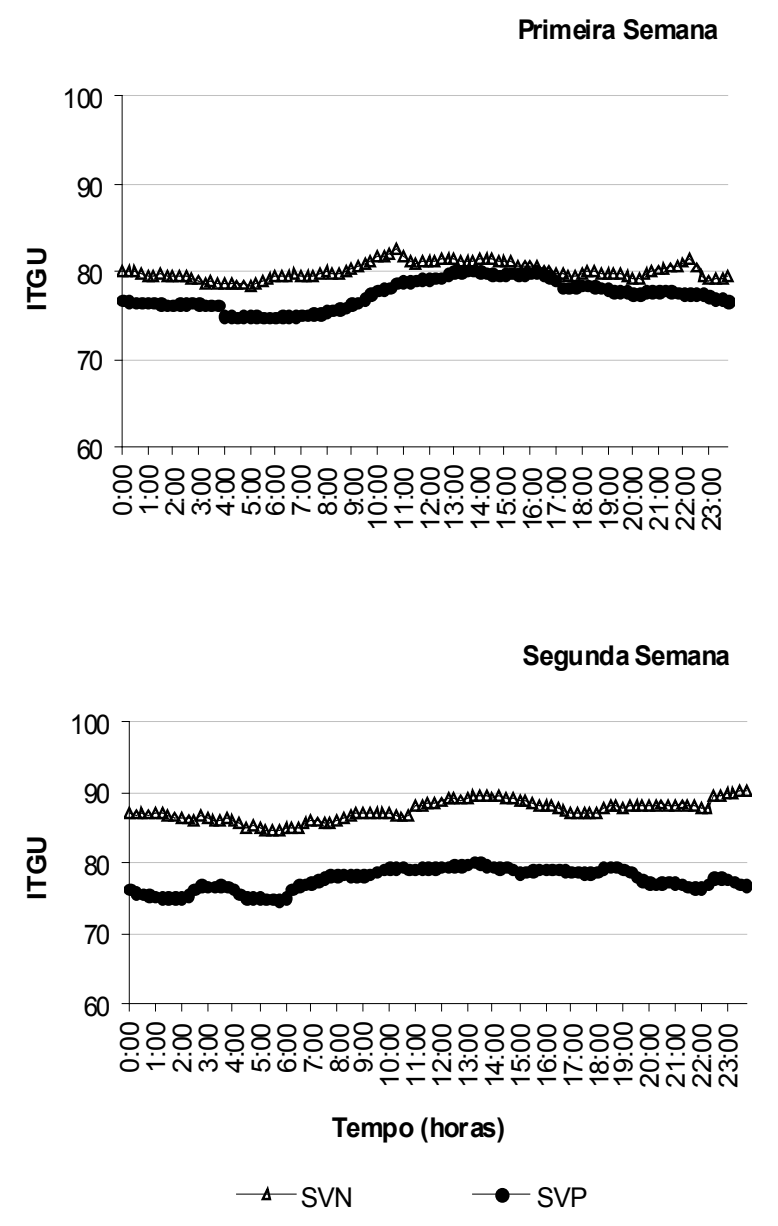

Figura 5. Médias do índice de temperatura de globo negro e umidade (ITGU), no ambiente interno, em função dos horários na primeira e segunda semana de vida das aves.

Quadro 3. Resumo das análises de variância referentes aos efeitos dos tratamentos sobre o índice de temperatura de globo negro e umidade (ITGU) no interior das instalações.

\begin{tabular}{|c|c|c|c|c|c|}
\hline \multirow{3}{*}{ FONTE DE VARIAÇÃO } & \multirow{3}{*}{ G.L. } & \multicolumn{4}{|c|}{ ITGU } \\
\hline & & \multicolumn{4}{|c|}{ QUA DRA DOS MÉDIOS } \\
\hline & & $1^{\text {a }}$ semana & $2^{\mathrm{a}}$ semana & $3^{a}$ semana & $4^{\mathrm{a}}$ semana \\
\hline LOTE & 1 & $498,119 * *$ & $192,723 \mathrm{n} . \mathrm{s}$ & $1163,54 \mathrm{n} . \mathrm{s}$ & $2928,58 \mathrm{n} . \mathrm{s}$ \\
\hline TRATAMENTO & 1 & $692,885 * *$ & $9106,63 * *$ & $24581,6 * *$ & $8254,14 *$ \\
\hline RESÍDUO (a) & 1 & 81,3867 & 195,129 & 2320,3 & 4929,95 \\
\hline HORA & 95 & $5,9928 * *$ & 7,1961 n.s & $6,15019 * *$ & $20,7577 * *$ \\
\hline HORA XTRAT. & 95 & $1,36354 \mathrm{n} . \mathrm{s}$ & 1,83863 n.s & $1,63496 \mathrm{n} . \mathrm{s}$ & $1,172 \mathrm{n} . \mathrm{s}$ \\
\hline RESÍDUO (b) & 190 & 1,97095 & 7,19705 & 4,29005 & 1,26766 \\
\hline C.V. $(\%)$ PA RCELA & & 11,45 & 16,92 & 57,36 & 90,08 \\
\hline C.V. $(\%)$ SUBPA RCELA & & 1,78 & 3,25 & 2,47 & 1,44 \\
\hline
\end{tabular}


Observa-se, por meio da Figura, que também nesta semana do experimento os valores de ITGU foram maiores no tratamento $\mathrm{SVN}$, sendo que, na maior parte do tempo, esses índices estiveram superiores a 85, o que indica desconforto para as aves. Segundo Teixeira (1983), em experimento com frangos de corte, ITGU com valores entre 67,4 e 75,6 levam a pior conversão alimentar e redução no ganho de peso, afetando negativamente a produtividade.

$\mathrm{Na}$ Figura 6, estão representados os resultados médios dos valores de ITGU para os tratamentos SVN e SVP, referentes à terceira e quarta semana de vida das aves.
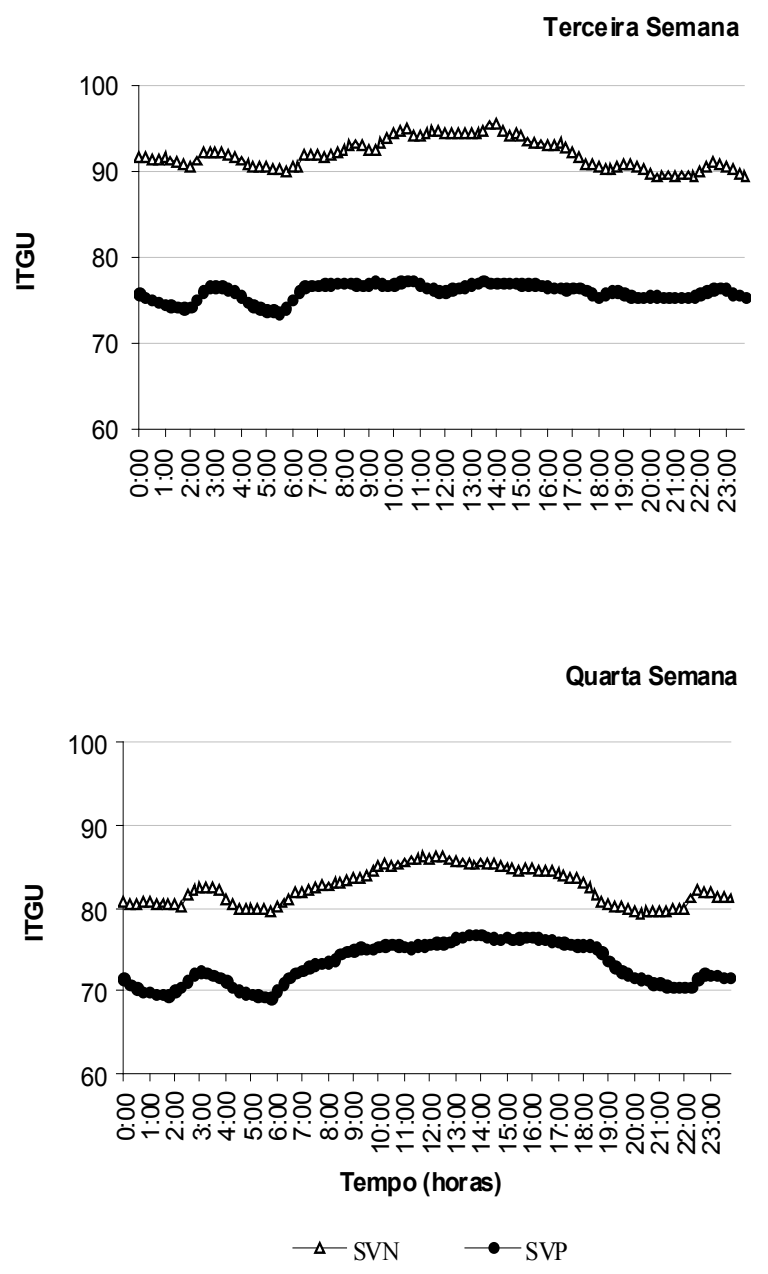

Figura 6. Médias do índice de temperatura de globo negro e umidade (ITGU), no ambiente interno, em função dos horários na terceira e quarta semana de vida das aves.

Por meio da Figura 6, verifica-se que os valores de ITGU, correspondentes ao tratamento SVN, apresentam-se maiores que os observados no SVP. Já os valores médios de ITGU, máximo de 77,2 e mínimo 73,6, encontrados no SVP, são considerados níveis de conforto, concordando com aqueles apresentados por Teixeira (1983), que observou valor do ITGU igual a 76 como limite crítico superior para frangos de corte de 21 a 50 dias de idade.

Com relação aos valores de ITGU referentes à quarta semana do experimento, verifica-se que os maiores valores ocorreram entre 12 e $14 \mathrm{~h}$. Comportamentos semelhantes foram verificados por vários autores, como Piasentin (1984), Tinôco (1988), Zanolla (1998) e Matos (2001). Segundo esses autores, frangos de corte acima de 15 dias de idade sofrem por desconforto quando estão em ambientes com ITGU superiores a 75. Assim, no presente estudo e na quarta semana de vida das aves, 0 tratamento SVN apresentou situações de desconforto para todos os horários medidos, enquanto, para o sistema SVP, os valores se mostraram dentro das faixas confortáveis.

Éimportanteressaltarque os tratamentos em estudo possuíam densidades de alojamento diferenciadas e o SVN possuía maior número de aves alojadas por $\mathrm{m}^{2}$. No entanto, é possível atribuir a este fato o aumento na dissipação de calor para o ambiente, resultante da ação dos mecanismos fisiológicos das aves para manutenção de sua homeotermia, manifestando condições desconfortáveis ao ambiente térmico.

Em condições de verão tem-se verificado, no interior dos aviários, valores de ITGU acima de 76 , o que inibe o desempenho produtivo das aves e constitui um dos principais problemas para sua criação (CURT

\section{Desempenho animal}

Valores médios de peso vivo das aves (PV), em $\mathrm{kg}$, conversão alimentar (CV), em kg de ração por $\mathrm{kg}$ de ganho de peso, e taxa de mortalidade (TM), em \%, para cada semana de observação, nos dois sistemas de ventilação avaliados (SVN e SVP), estão apresentados no Quadro 4.

Verificou-se que não houve influência dos diferentes sistemas de ventilação em nenhuma das semanas de vida das aves, nas variáveis de desempenho animal.

Por meio do Quadro 4, pode-se observar a evolução do peso vivo das aves com base nos valores médios semanais registrados. Observa-se um aumento sustentado do PV das aves, ao longo das quatro semanas de vida, para ambos os sistemas e, ainda, que no SVP o PV médio das aves foi ligeiramente maior em todas as semanas. 
Quadro 4. Médias de peso vivo (PV) em kg, consumo de ração (CR) em kg/ave, ganho de peso (GP) em kg/ave, conversão alimentar (CV) em kg de ração/kg de ganho de peso e taxa de mortalidade (TM), em \%, para frangos de corte em cada semana de vida, e submetidos a diferentes sistemas de criação.

\begin{tabular}{|c|c|c|c|c|c|}
\hline \multirow{2}{*}{ Parâmetros Zootécnicos } & \multirow{2}{*}{ Sistemas } & \multicolumn{4}{|c|}{ Idade das aves } \\
\hline & & $1-7$ dias & $8-14$ dias & $15-21 \mathrm{~d}$ ias & $22-28$ dias \\
\hline \multirow{2}{*}{ Peso Vivo (kg) } & $\mathrm{SVN}$ & $0,166 \mathrm{a}$ & $0,389 \mathrm{a}$ & $0,787 \mathrm{a}$ & $1,206 \mathrm{a}$ \\
\hline & SVP & $0,177 \mathrm{a}$ & $0,415 \mathrm{a}$ & $0,819 \mathrm{a}$ & $1,239 \mathrm{a}$ \\
\hline \multirow{2}{*}{ Consumo de ração (kg/ave) } & $\mathrm{SVN}$ & $0,1857 \mathrm{a}$ & $0,5291 \mathrm{a}$ & $0,7988 \mathrm{a}$ & $0,8024 \mathrm{a}$ \\
\hline & S VP & $0,1711 \mathrm{a}$ & $0,5531 \mathrm{a}$ & $0,7409 \mathrm{a}$ & $0,7835 \mathrm{a}$ \\
\hline \multirow{2}{*}{ Ganho de Peso (kg/ave) } & $\mathrm{SVN}$ & $0,121 \mathrm{a}$ & $0,224 \mathrm{a}$ & $0,398 \mathrm{a}$ & $0,419 \mathrm{a}$ \\
\hline & S VP & $0,132 \mathrm{a}$ & $0,238 \mathrm{a}$ & $0,404 \mathrm{a}$ & $0,420 \mathrm{a}$ \\
\hline \multirow{2}{*}{$\begin{array}{c}\text { Conversão Alimentar } \\
\text { (kg de ração/kg de ganho de } \\
\text { peso) }\end{array}$} & SVN & $1,547 \mathrm{a}$ & $2,377 \mathrm{a}$ & $2,002 \mathrm{a}$ & $1,949 \mathrm{a}$ \\
\hline & SVP & $1,296 \mathrm{a}$ & $2,326 \mathrm{a}$ & $1,928 \mathrm{a}$ & $1,775 \mathrm{a}$ \\
\hline \multirow{2}{*}{ Taxa de mortalidade (\%) } & SVN & $0,794 \mathrm{a}$ & $0,315 \mathrm{a}$ & $0,149 \mathrm{a}$ & $0,215 \mathrm{a}$ \\
\hline & SVP & $0,596 \mathrm{a}$ & $0,294 \mathrm{a}$ & $0,182 \mathrm{a}$ & $0,155 \mathrm{a}$ \\
\hline
\end{tabular}

As médias seguidas de pelo menos uma mesma letra na coluna, não diferem entre si a 15\% de probabilidade pelo teste de Tukey.

Quanto ao consumo relativo ao longo das semanas, para os dois tratamentos, ocorreu um aumento considerável no consumo de ração nas três primeiras semanas e praticamente estagnação na quarta semana. Isto, provavelmente, devido a uma alimentação de elevado conteúdo protéico nas duas primeiras semanas de vida das aves, estimulando um crescimento precoce nos frangos, segundo Valverde (2001). Comportamento semelhante foi observado também por Tinôco (1996), Fonseca (1998), Zanolla (1998), Matos (2001) e Silva (2002).

Vale ressaltar que, embora o consumo de ração praticamente não tenha aumentado da terceira para a quarta semana de vida das aves, registrou-se considerável aumento no ganho de peso, provavelmente em decorrência de melhores condições térmicas ambientais na quarta semana experimental, conforme indicadas pelos resultados de ITGU. Comportamento similar também foi verificado por Zanolla (1998).

Embora não estatisticamente significativa, no final das quatro semanas verificou-se uma média de ganho de peso de $32 \mathrm{~g}$ por ave, a mais, no tratamento SVP, comparado ao SVN. Isto permite inferir que não só o ambiente térmico interfere na produtividade final, mas, também, que outras variáveis, como comportamento social, luz, ruídos, dentre outros, podem estar interferindo.

Os valores médios de CA tiveram comportamentos semelhantes para os dois tratamentos. De forma geral, como as condições térmicas ambientais, com base no ITGU, foram melhores no SVP, presume-se que as aves consumiram menor quantidade de ração e tiveram maior ganho de peso, verificando-se, assim, uma melhor conversão alimentar (Quadro 4).

Observa-se, também, que os maiores índices de mortalidade foram registrados nas fases iniciais de alojamento, ou seja, na primeira e segunda semana de vida das aves, fato este considerado normal, uma vez que nesta fase as aves encontram-se mais sensíveis às condições térmicas e à qualidade do ar e mais predispostas a doenças.

\section{CONCLUSÕES}

- De maneira geral, a temperatura interna média do ar não correspondeu àquela considerada de conforto térmico para as aves. Isto se deve provavelmente a falhas nos fechamentos das instalações e no aquecimento, pois, por causa do período de inverno com frio intenso, ocorreu grande amplitude térmica entre o ambiente externo e interno, dificultando a supressão para o aquecimento satisfatório.

- Os índices de conforto térmico ambiente ITGU e umidade relativa do ar, no interior das instalações, apresentaram comportamento semelhante para os dois tratamentos SVN e SVP. Para a umidade relativa do ar entre 60 e $70 \%$ para ambos os tratamentos, foram verificados níveis satisfatórios para um bom desenvolvimento do plantel. Com relação ao ITGU, os valores mostraram-se sempre superiores para o SVN, com as maiores amplitudes na segunda e 
terceira semana de vida, e as melhores condições de conforto ambiente foram observadas no SVP.

- Em relação aos índices de desenvolvimento produtivo das aves, para os parâmetros peso vivo (PV) e conversão alimentar (CA) os melhores resultados foram obtidos no SVP, com valores ligeiramente superiores em consumo de ração (CR) e taxa de mortalidade (TM) no SVN. Contudo, os dois tratamentos apresentaram produtividade final dentro da faixa considerada satisfatória pela avicultura nacional de corte.

\section{AGRADECIMENTOS}

Os autores agradecem à Universidade Federal de Viçosa, à Perdigão Agroindustrial S.A. e em especial à CAPES, ao CNPq e à FAPEMIG pelo apoio e suporte financeiro à pesquisa, bolsa de pósgraduação e de iniciação científica.

\section{REFERÊNCIAS BIBLIOGRÁFICAS}

AGROCERES. Manejo dos pintos. In: Manual de manejo de frango de corte AGROSS, Rio Claro SP, 1997. p.9-13.

CURTIS, S.E. Environmental management in animal agriculture. Ames: The Iowa State University Press, 1983. 409p.

EPAGRI. Caracterização geral. Disponível em: $<$ www.epagri.rctsc.br.> Acesso em: 20 de junho de 2005.

FONSECA, J.M. Efeito da densidade de alojamento sobre o desempenho de frangos de corte criados em sistema de nebulização e ventilação em túnel. 1998, 57 f. Dissertação (Mestrado em Engenharia Agrícola) - Universidade Federal de Viçosa, Viçosa, MG, 1998.

JENTZSCH, R. Estudo de modelos reduzidos destinados à predição de parâmetros térmicos ambientais em instalações agrícolas. 2002, 113 f. Tese (Doutorado em Engenharia Agrícola) Universidade Federal de Viçosa,Viçosa, MG, 2002.

MACARI, M., FURLAN, R.L., GONZALES, E. Fisiologia aviária aplicada a frangos de corte. 2.ed. ampl. Jaboticabal: FUNEP/UNESP, 2002. 296p.
MATOS, M.L. Conforto térmico ambiente e desempenho de frangos de corte, alojados em dois níveis de densidade, em galpões com sistema de ventilação em túnel e lateral. 2001, 89 f. Dissertação (Mestrado em Engenharia Agrícola) - Universidade Federal de Viçosa,Viçosa, MG, UFV, 2001.

MORAES, S.R.P. Caracterização de sistemas de semiclimatização de ambiente, em galpões para frango de corte, no sudoeste de Goiás. 2002, 148 f. Tese (Doutorado em Engenharia Agrícola) - Universidade Federal de Viçosa, Viçosa, MG, 2002.

PIASENTIN, J.A. Conforto medido pelo índice de temperatura de globo negro e umidade relativa na produção de frangos de corte para dois tipos de pisos em Viçosa, MG. 1984, $98 \mathrm{f}$. Dissertação (Mestrado em Engenharia Agrícola) Universidade Federal de Viçosa, 1984.

SILVA, C.E. Comparação de painéis evaporativos de argila expandida e celulose para sistema de resfriamento adiabático do ar em galpões avícolas com pressão negativa em modo túnel. 2002, 67 f. Dissertação (Mestrado em Engenharia Agrícola) - Universidade Federal de Viçosa,Viçosa, MG, 2002.

TEIXEIRA, V.H. Estudo dos índices de conforto em duas instalações de frango de corte para as regiões de Viçosa e Visconde do Rio Branco - MG. 1983, 62 f. Dissertação (Mestrado em Engenharia Agrícola) - Universidade Federal de Viçosa. Viçosa, MG, 1983.

TINÔCO, I.F.F. Resfriamento adiabático (evaporativo) na produção de frangos de cortes. 92 f. Dissertação (Mestrado em Engenharia Agrícola) - Universidade Federal de Viçosa, Viçosa, MG,1988.

TINÔCO, I.F.F. Conforto ambiental para aves/ ponto de vista do engenheiro. In. Simpósio Goiano de Avicultura (2: 1995: Goiânia-Goiás). Anais... do II Simpósio Goiano de Avicultura - Goiânia, 1996. p.47-56.

TINÔCO, I.F.F., RESENDE, P.L. Produção de 
frango de corte em alta densidade. Viçosa: Manual CPT - Centro de Produções Técnicas, 1997. 20p.

UBA. Relatório anual 2005/2006. Disponível em: <www.uba.org.br.> Acesso em 10 Jan. 2007.

VALVERDE, C.C. 250 maneiras de preparar rações balanceadas para frangos de corte.

Viçosa: Aprenda fácil, 2001. 261p.: il. 2001.

ZANOLLA, N. Sistema de ventilação em túnel e sistema de ventilação lateral na criação de frangos de corte em alta densidade. 1998, $81 \mathrm{f}$. Dissertação (Mestrado em Engenharia Agrícola) Universidade Federal de Viçosa, Viçosa, MG,1998. 